\title{
Characterization of Microstructure on Porous Silicon Carbide Prepared by Polymer Replica Template Method
}

\author{
Yoon Joo Lee, Soo Ryong Kim, Young Hee Kim, Dong Geun Shin, Ji Yeon Won, and Woo Teck Kwon ${ }^{\dagger}$ \\ Energy \& Environmental Division, Korea Institute of Ceramic and Technology, Seoul 153-801, Korea \\ (Received October 2, 2014; Revised November 11, 2014; Accepted November 12, 2014)
}

\section{고분자 복제 템플릿 방법을 이용하여 제조된 다공성 탄화규소의 미세구조 특성}

\author{
이윤주 · 김수룡 · 김영희 · 신동근 · 원지연 · 권우택 \\ 한국세라믹기술원 에너지환경소재본부 \\ (2014년 10월 2일 접수 ; 2014년 11월 11일 수정 ; 2014년 11월 12일 채택)
}

\begin{abstract}
Foam type porous silicon carbide ceramics were fabricated by a polymer replica method using polyurethane foam, carbon black, phenol resin, and silicon powder as raw materials. The influence of the $\mathrm{C} / \mathrm{Si}$ mole ratio of the ceramic slurry and heat treatment temperature on the porous silicon carbide microstructure was investigated. To characterize the microstructure of porous silicon carbide ceramics, BET, bulk density, X-ray Powder Diffraction (XRD), and Scanning Electron Microscope (SEM) analyses were employed. The results revealed that the surface area of the porous silicon carbide ceramics decreases with increased heat treatment temperature and carbon content at the $2^{\text {nd }}$ heat treatment stage. The addition of carbon to the ceramic slurry, which was composed of phenol resin and silicon powder, enhanced the direct carbonization reaction of silicon. This is ascribed to a consequent decrease of the wetting angles of carbon to silicon with increasing heat treatment temperature.
\end{abstract}

Key words : Porous, Silicon carbide, Microstructure, Thermal property, Foam

\section{1. 서 론}

특정한 기공특성과 미세구조를 갖는 세라믹 다공체는 일반적인 치밀질 구조체와는 다른 특성을 발현할 수 있 다. 따라서 최근에는 세라믹 고유의 열적 안정성, 화학 저 항성뿐만 아니라 다공체가 갖는 높은 비표면적과 경량특 성 등을 활용한 새로운 용도로의 활용이 증가하고 있다. 특히 탄화규소 다공체는 탄화규소 고유의 우수한 특성인 고온내열성 및 높은 열전도 특성 외에 높은 비표면적, 경 량성 및 통기성을 부여함으로써 고온가스필터, 축열재, 수 처리용 필터 및 촉매 지지체와 같은 새로운 분야로의 적 용이 확대되고 있다. ${ }^{1-5)}$ 다공성 세라믹 소재의 미세구조 와 기공특성은 사용하는 원료뿐만 아니라 제조방법에 따 라서 민감한 영향을 받는다.

다공성 세라믹스의 제조방법은 다공체의 골격구조 및 기공을 형성하는 방법에 따라서 복제 템플릿(replica template) 방법, 희생 템플릿(sacrificial template) 방법 및

${ }^{\dagger}$ Corresponding author: Woo Teck Kwon

E-mail : wtkwon@kicet.re.kr

Tel : +82-2-3282-2425 Fax : +82-2-3282-2430
가스를 세라믹 슬러리에 직접 불어넣고 건조와 소결과정 을 통하여 기공을 형성하는 직접 기공형성(direct foaming) 방법으로 구분할 수 있다. ${ }^{67)}$ 복제 템플릿 방법은 다공체 를 제조하는 과정에서 사용된 템플릿의 형상을 유지할 수 있는 방법으로서 폴리우레탄 폼과 같은 고분자 복제 템 플릿에 탄화규소 소결체를 형성할 수 있는 세라믹 슬러 리 원료를 함침한 후에 열처리 과정을 거쳐서 고분자를 제거하는 방법이다. 고분자 복제 템플릿 방법은 사용하는 목적 및 용도에 따라서 폴리우레탄과 같은 합성 고분자 외에 나무나 탄소 폼을 사용하기도 한다. ${ }^{8)}$ 고분자 복제 템플릿 방법은 희생 템플릿이나 직접기공형성 방법과 비 교하여 기공율이 높거나 열린 기공(open pore)을 갖는 세 라믹 다공체 제조에 유리한 것으로 알려져 있다. ${ }^{6}$ 하지만 템플릿으로 사용하는 고분자가 열처리과정에서 빈 공간 으로 남게 되어 기계적 강도가 약하고, 구조적인 압력으 로 인하여 쉽게 균열이 발생하는 문제점이 발생하며, 소결 과정에서 수축되어 형상유지가 쉽지 않은 것으로 알려져 있다. ${ }^{9,10)}$ 이러한 문제점을 해결하기 위한 다양한 연구가 시 도 되었으며, Zhu 등은 고분자 템플릿에 세라믹 코팅공정 을 2단계로 나누어서 진행하는 방법을 도입하였고, ${ }^{11)}$ 
Nangrejo와 Edirisinghe는 세라믹 전구체를 원료로 사용하 였다. ${ }^{12)}$ 사용원료는 용도나 목적에 따라서 탄화규소 분말 이나 탄화규소 세라믹 전구체를 사용하기도 하지만 제조 공정이나 경제성을 고려하여 실리콘과 카본을 원료로 사 용하는 것이 일반적이다.

본 연구에서는 고분자 복제 템플릿 방법을 이용하여 다 공성 탄화규소를 제조하였으며, 원료배합 및 열처리 조건 변화가 소결체의 기공 및 미세조직 특성에 미치는 영향 을 살펴보고자 하였다. 실리콘과 카본을 원료로 하는 자 기결합 탄화규소 세라믹스(self-bonded $\mathrm{SiC}$ ceramics) 반응 을 적용하였으며, 기공형성을 위한 고분자 템플릿으로 폴 리우레탄 폼을 이용하였다. 원료조건 변화가 소결체의 미 세구조 특성에 대한 영향을 살펴보기 위해서 실리콘과 카 본함량을 변화시키면서 실험하였다. 또한 열처리 조건 변 화에 대한 영향을 파악하기 위해서 $1420^{\circ} \mathrm{C}$ 에서의 1 차 열 처리와 실리콘 함침을 위한 $1550^{\circ} \mathrm{C}$ 에서의 2 차 열처리 반 응을 분리해서 열처리 단계별로 소결체의 기공 및 미세 구조 특성변화를 살펴보았다.

\section{2. 실험 방법}

고순도 실리콘 분말( $\mathrm{Si} 98.7 \%, \mathrm{SiO}_{2} 1.3 \%$, 평균입경 $3.5 \mu \mathrm{m}$, $\mathrm{ACM}$ 사, 한국)과 카본블랙(MA100, 평균입경 $0.36 \mu \mathrm{m}$, 미쓰 비시사, 일본)을 고분자 복제 템플릿방법 적용을 위한 세 라믹 슬러리의 주 원료로 이용하였다. 세라믹 슬러리를 고분자 템플릿에 잘 코팅되도록 점착성을 부여하고 자기 결합 탄화규소 세라믹스(self-bonded $\mathrm{SiC}$ ceramics) 반응에 서 탄소 원을 공급하기 위한 원료로서 페놀수지(코오롱사, 한국)를 사용하였다. 고분자 템플릿으로서 폴리우레탄 폼 을 사용하였으며, 열처리와 소결을 용이하게 할 수 있도 록 일정한 크기 $(3 \mathrm{~cm} \times 3 \mathrm{~cm} \times 3 \mathrm{~cm})$ 로 절단하였다. 폴리우 레탄 폼에 코팅할 세라믹 슬러리는 페놀수지와 에탄올을 $1: 2$ 로 희석한 후에 카본블랙과 실리콘 분말을 혼합하여 제조하였다. 이때 카본블랙과 실리콘 분말의 몰비를 1.0 , 1.5 및 2.0로 변화하여 카본과 실리콘 함량에 따른 실리 콘카바이드 폼의 미세조직과 기공특성 변화를 살펴보고 자 하였다. 폴리우레탄 폼에 세라믹 슬러리를 코팅하기 위하여 함침 공정을 적용하였으며, 균일한 코팅을 위하여 세라믹 슬러리에 5 분이상 충분히 함침한 후에 1 단계로 핀 셋을 이용하여 세라믹 슬러리를 제거하고, 2 단계로 롤러 를 이용하여 폴리우레탄 폼에 세라믹 슬러리를 균일하게 코팅되도록 하였다. 세라믹 슬러리가 코팅된 폴리우레탄 폼은 건조기에서 $100^{\circ} \mathrm{C}, 24$ 시간 건조과정을 거친 후에 $1420^{\circ} \mathrm{C}$ 에서 1 시간 동안 열처리 하였다. 1차 열처리 온도 는 열처리 후에 다공성 탄화규소의 기계적 강도가 적정 수준 유지되도록 하고자 하였다. 이를 위해서 세라믹 슬 러리에 포함되어 있는 실리콘과 탄소성분이 반응하여 탄
화규소가 생성되는 온도를 고려하였으며, 기존의 연구결 과 ${ }^{5)}$ 를 참고하여 $1420^{\circ} \mathrm{C}$ 로 정하였다. 1 차 열처리 $\left(1420^{\circ} \mathrm{C}\right.$, 1 시간) 후에 다공성 탄화규소를 치밀하게 하고 미반응 탄 소를 탄화규소로 전환하기 위하여 실리콘분말을 페놀수 지 및 에탄올과 혼합하여 코팅한 후, 2 차 열처리 $\left(1550^{\circ} \mathrm{C}\right.$, 1 시간)를 진행하였다. 열처리 공정은 아르곤 분위기에서 진행하였으며 승온속도는 $10^{\circ} \mathrm{C} / \mathrm{min}$ 을 유지하였다. 슬러리 용액에서 카본과 실리콘 함량 변화와 열처리과정에서의 소결특성 변화를 파악하기 위하여 다공성 탄화규소 폼의 기공특성, 밀도, 광물생성 및 미세구조 변화를 측정하였 다. 기공특성 변화는 $\mathrm{BET}$ 비표면적 측정기(Micromeritics, ASAP 2010)를 이용하여 측정하였다. 밀도변화는 열처리 전, 후의 열처리 소결체의 무게와 부피를 직접 측정하였 으며, 결정상은 X-선 회절분석기(P/MAX 2200V/PC, Rigaku Corp.)를 사용하였다. 미세구조는 주사전자현미경(Scanning Electron Microscopy, SEM: S-4100, HITACHI)과 EDS (Energy-dispersive X-ray spectrometer, Genesis 2000 XMS, $\mathrm{USA})$ 를 이용하여 측정하였다.

\section{3. 결과 및 고찰}

Fig. 1은 폴리우레탄 폼 함침 슬러리에서 카본과 실리 콘 $(\mathrm{C} / \mathrm{Si})$ 의 몰비를 $1.0,1.5$ 및 2.0 으로 변화시키면서 $1420^{\circ} \mathrm{C}$ 에서 열처리하여 제조한 다공성 세라믹 시료의 비 표면적 변화를 $\mathrm{BET}$ 를 이용하여 측정한 결과이다. Fig. 1 에서 볼 수 있듯이, $1420^{\circ} \mathrm{C}$ 열처리 조건에서 카본과 실리 콘 $(\mathrm{C} / \mathrm{Si})$ 의 몰비가 $1.0,1.5$ 및 2.0 으로 증가함에 따라서 열 처리물의 비표면적이 $61.15 \mathrm{~m}^{2} / \mathrm{g}, 75.08 \mathrm{~m}^{2} / \mathrm{g}$ 및 $104.54 \mathrm{~m}^{2} / \mathrm{g}$ 으로 증가하여 카본함량 증가에 따른 비표면적 증가를 확 인할 수 있었다. 탄화규소의 비표면적 및 기공크기와 같 은 기공특성은 사용하는 원료의 종류, 제조온도, 체류시 간뿐만 아니라 다공체의 형성방법과 같은 다양한 요인에

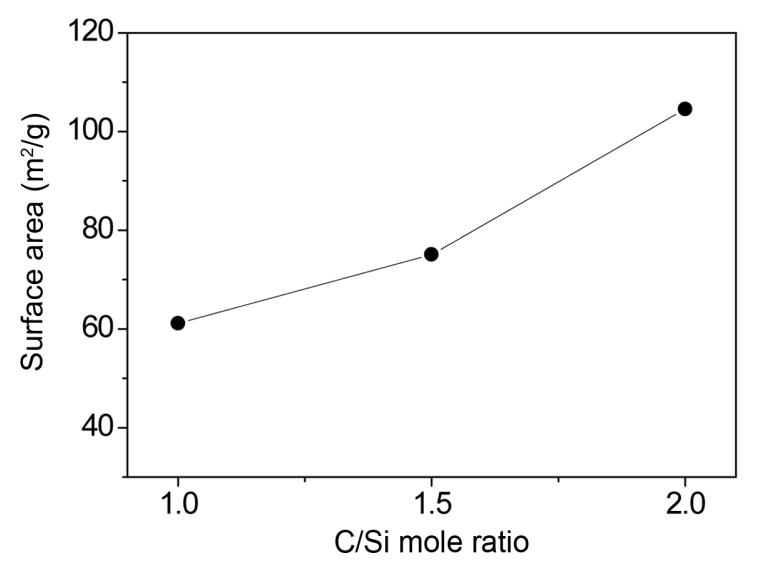

Fig. 1. BET surface area results with different $\mathrm{C} / \mathrm{Si}$ mole ratios $(1.0,1.5,2.0)$ after heat treatment at $1420^{\circ} \mathrm{C}$. 


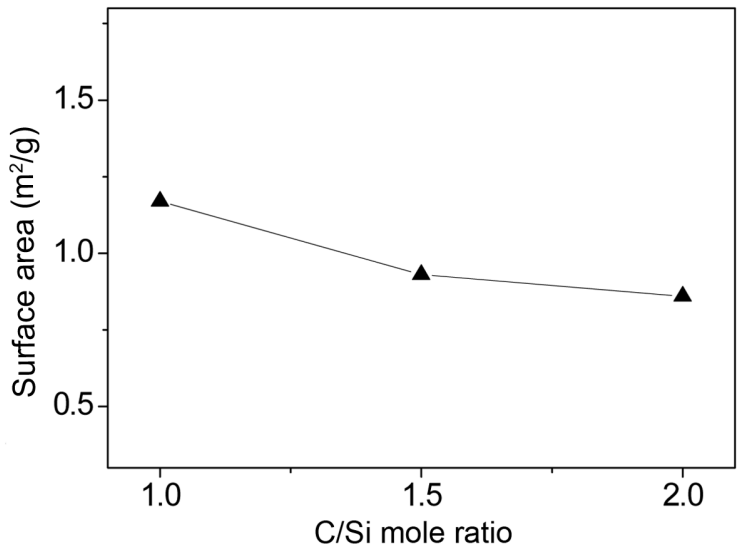

Fig. 2. BET surface area results with different $\mathrm{C} / \mathrm{Si}$ mole ratios $(1.0,1.5,2.0)$ after $2^{\text {nd }}$ heat treatment at $1550^{\circ} \mathrm{C}$.

의하여 변화하며, ${ }^{6,13,14)}$ 카본성분은 고온 열처리 및 활성 화 과정을 통하여 비표면적이 증가하는 것으로 알려져 있 다. ${ }^{15)}$ 따라서 본 실험에서 카본과 실리콘 $(\mathrm{C} / \mathrm{Si})$ 의 몰비가 증가함에 따라서 비표면적이 증가하는 것은 $1420^{\circ} \mathrm{C}$ 에서 실리콘과 반응하지 않은 카본성분에 의한 것으로 판단된 다. $\mathrm{C} / \mathrm{Si}$ 의 몰비를 변화하면서 $1420^{\circ} \mathrm{C}$ 에서 열처리한 시료 에 실리콘 분말을 코팅하여 2 차 열처리 $\left(1550^{\circ} \mathrm{C}, 1\right.$ 시간 $)$ 하 여 제조한 시료에 대한 $\mathrm{BET}$ 측정결과를 Fig. 2에 나타내 었다. 측정결과로부터 알 수 있듯이, 실리콘 분말을 코팅 하여 $1550^{\circ} \mathrm{C}$ 에서 열처리한 경우에는 $\mathrm{BET}$ 측정값이 0.86 $1.17 \mathrm{~m}^{2} / \mathrm{g}$ 으로 급격히 저하됨을 확인할 수 있었다. 특히 $1420^{\circ} \mathrm{C}, 1$ 차 열처리과정에서 $\mathrm{C} / \mathrm{Si}$ 몰비가 $1.0,1.5$ 및 2.0 으로 증가하여 비표면적이 각각 $61.15 \mathrm{~m}^{2} / \mathrm{g}, \quad 75.08 \mathrm{~m}^{2} / \mathrm{g}$ 및 $104.54 \mathrm{~m}^{2} / \mathrm{g}$ 으로 증가한 반면, 실리콘 분말을 코팅하여 $1550^{\circ} \mathrm{C}$ 에서 열처리한 시료의 비표면적은 $1.17 \mathrm{~m}^{2} / \mathrm{g}, 0.93 \mathrm{~m}^{2} / \mathrm{g}$ 및 $0.86 \mathrm{~m}^{2} / \mathrm{g}$ 으로 오히려 감소함을 알 수 있었다. 일반적으로 $\mathrm{Si}$ 과 $\mathrm{C}$ 의 반응은 온도와 시간이 증가할수록 wetting angle 은 감소되며 $1600^{\circ} \mathrm{C}$ 에서 카본에 대한 $\mathrm{Si}$ 의 접촉각이 $0^{\circ}$ 에 가까운 것으로 알려져 있다. ${ }^{16,17)}$ 따라서 $1420^{\circ} \mathrm{C}$ 에서 열처리한 $\mathrm{SiC} / \mathrm{Si} / \mathrm{C}$ 소결체에서 카본성분은 추가로 첨가되 는 $\mathrm{Si}$ 과 $1550^{\circ} \mathrm{C}$ 에서 쉽게 반응하여 $\mathrm{SiC}$ 로 쉽게 전환된 것 으로 판단된다. 특히 $\mathrm{C} / \mathrm{Si}$ 몰비가 높아서 카본성분이 많
을수록 $1550^{\circ} \mathrm{C}$ 에서 용융 $\mathrm{Si}$ 과 카본성분과의 반응과정에 서 발열반응에 의한 온도증가 및 $\mathrm{SiC}$ 합성이 용이해지기 때문에 비표면적 감소량이 더욱 많아진 것으로 생각된다.

본 실험의 $\mathrm{C} / \mathrm{Si}$ 몰비 변화 및 2 단계 함침 과정을 갖는 열처리 온도 변화에 따른 비표면적 및 기공특성 변화를 Table 1에 요약하여 나타내었다. Table 1에 보는 바와 같 이 $1420^{\circ} \mathrm{C}$ 열처리 조건에서 $\mathrm{C} / \mathrm{Si}$ 몰비가 $1.0,1.5$ 및 2.0 으로 증가할수록 비표면적이 $61.15 \mathrm{~m}^{2} / \mathrm{g}, 75.08 \mathrm{~m}^{2} / \mathrm{g}$ 및 $104.54 \mathrm{~m}^{2} / \mathrm{g}$ 으로 증가하는 것과는 달리 평균 기공 경은 각 각 $111.2 \AA, 103.5 \AA$ 및 $90.2 \AA$ 으로 감소하는 것으로 알 수 있다. 하지만 기공의 부피는 $\mathrm{C} / \mathrm{Si}$ 몰비가 $1.0,1.5$ 및 2.0 으로 증가 할수록 $0.09 \mathrm{~cm}^{3} / \mathrm{g}, 0.11 \mathrm{~cm}^{3} / \mathrm{g}$ 및 $0.14 \mathrm{~cm}^{3} / \mathrm{g}$ 으로 증가하였다. $\mathrm{Si}$ 슬러리를 함침하여 $1550^{\circ} \mathrm{C}$ 에서 열처 리한 경우에는 $1420^{\circ} \mathrm{C}$ 에서 열처리한 경우와는 다르게 $\mathrm{C} /$ $\mathrm{Si}$ 몰비가 $1.0,1.5$ 및 2.0 으로 증가 할수록 비표면적이 $1.17 \mathrm{~m}^{2} / \mathrm{g}, 0.93 \mathrm{~m}^{2} / \mathrm{g}$ 및 $0.86 \mathrm{~m}^{2} / \mathrm{g}$ 으로 감소하였으며 평균 기공경도 각각 $170.2 \AA, 154.4 \AA$ 및 $135.9 \AA$ 으로 감소하 였다. 또한 기공의 부피도 $\mathrm{C} / \mathrm{Si}$ 몰비가 $1.0,1.5$ 및 2.0 으로 증가 할수록 $0.004 \mathrm{~cm}^{3} / \mathrm{g}, 0.003 \mathrm{~cm}^{3} / \mathrm{g}$ 및 $0.002 \mathrm{~cm}^{3} / \mathrm{g}$ 로 감소 하였으며, 이러한 결과는 $\mathrm{Si}$ 이 카본성분과 반응하여 $\mathrm{SiC}$ 가 합성되는 과정과 밀접한 관련이 있기 때문이라 생각된다.

Zhang등은 ${ }^{18)}$ 다공성 탄화규소를 제조하는 과정에서 카 본성분에 대한 실리콘의 함침량 변화가 다공성 세라믹의 특성을 좌우하며, 특히 기공율 및 밀도변화에 민감한 영 향을 미치는 것으로 보고하고 있다. 따라서 $\mathrm{C} / \mathrm{Si}$ 몰비 및 열처리 조건이 다공성 탄화규소의 밀도변화에 미치는 영 향을 파악하고자 하였으며 분석결과를 Fig. 3에 나타내었 다. 측정결과로부터 $\mathrm{C} / \mathrm{Si}$ 몰비가 $1.0,1.5$ 및 2.0으로 변화 함에 따라서 $1420^{\circ} \mathrm{C}$ 열처리 시료의 부피밀도가 $0.061 \mathrm{~g} / \mathrm{cm}^{3}$, $0.076 \mathrm{~g} / \mathrm{cm}^{3}$ 및 $0.083 \mathrm{~g} / \mathrm{cm}^{3}$ 으로 증가하였다. 특히 실리콘 을 함침한 후 $1550^{\circ} \mathrm{C}$ 에서 열처리한 경우에는 $0.156 \mathrm{~g} / \mathrm{cm}^{3}$, $0.206 \mathrm{~g} / \mathrm{cm}^{3}$ 및 $0.245 \mathrm{~g} / \mathrm{cm}^{3}$ 으로 $1420^{\circ} \mathrm{C}$ 에서 열처리한 시 료보다 2.5배이상 증가하였으며, 부피밀도의 증가비율도 $\mathrm{C} / \mathrm{Si}$ 몰비가 증가함에 따라서 더욱 커지는 것을 확인하였 다. 이렇게 $\mathrm{C} / \mathrm{Si}$ 몰비가 증가함에 따라서 소결체의 부피 밀도가 증가하는 것은 실리콘이 $1550^{\circ} \mathrm{C}$ 의 반응조건에서 카본과 좀 더 효율적으로 반응하기 때문이며, 궁극적으로

Table 1. Effect of Heat Treatment Temperatures and C/Si Mole Ratios on Porosity Characteristics

\begin{tabular}{|c|c|c|c|c|}
\hline \multirow{2}{*}{$\begin{array}{l}\text { Heat treatment } \\
\text { temperature }\left({ }^{\circ} \mathrm{C}\right)\end{array}$} & \multirow{2}{*}{$\begin{array}{c}\mathrm{C} / \mathrm{Si} \\
\text { mole ratio }\end{array}$} & \multirow{2}{*}{$\begin{array}{l}\text { Surface area (BET) } \\
\qquad\left(\mathrm{m}^{2} / \mathrm{g}\right)\end{array}$} & \multicolumn{2}{|c|}{ Porosity characteristics } \\
\hline & & & $\begin{array}{l}\text { Total pore volume } \\
\left(\mathrm{cm}^{3} / \mathrm{g}\right)\end{array}$ & $\begin{array}{c}\text { Average } \\
\text { pore diameter }(\AA)\end{array}$ \\
\hline \multirow{3}{*}{1420} & 1.0 & 61.15 & 0.09 & 111.2 \\
\hline & 1.5 & 75.08 & 0.11 & 103.5 \\
\hline & 2.0 & 104.54 & 0.14 & 90.2 \\
\hline \multirow{3}{*}{1550} & 1.0 & 1.17 & 0.004 & 170.2 \\
\hline & 1.5 & 0.93 & 0.003 & 154.4 \\
\hline & 2.0 & 0.86 & 0.002 & 135.9 \\
\hline
\end{tabular}




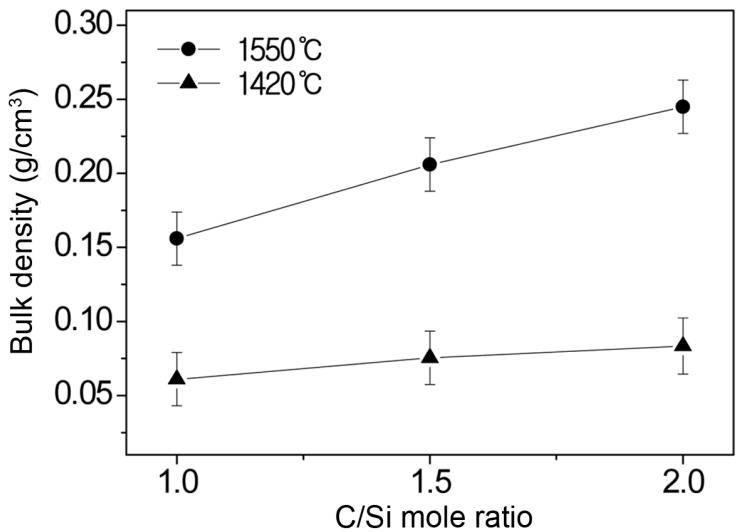

Fig. 3. Bulk density results with different $\mathrm{C} / \mathrm{Si}$ mole ratios $(1.0,1.5,2.0)$ after heat treatment $\left(1^{\mathrm{st}} 1420^{\circ} \mathrm{C}, 2^{\text {nd }}\right.$ $\left.1550^{\circ} \mathrm{C}\right)$.

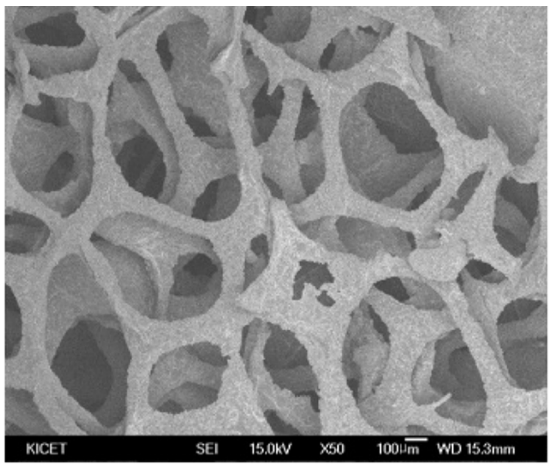

(a) $\mathrm{C} / \mathrm{Si}$ mole ratio : 1.0

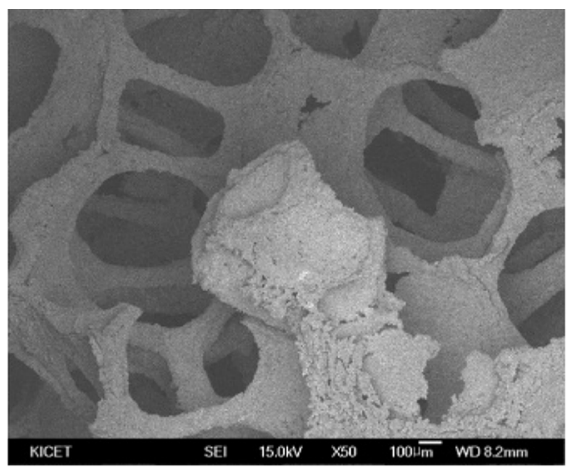

(b) $\mathrm{C} / \mathrm{Si}$ mole ratio : 1.5

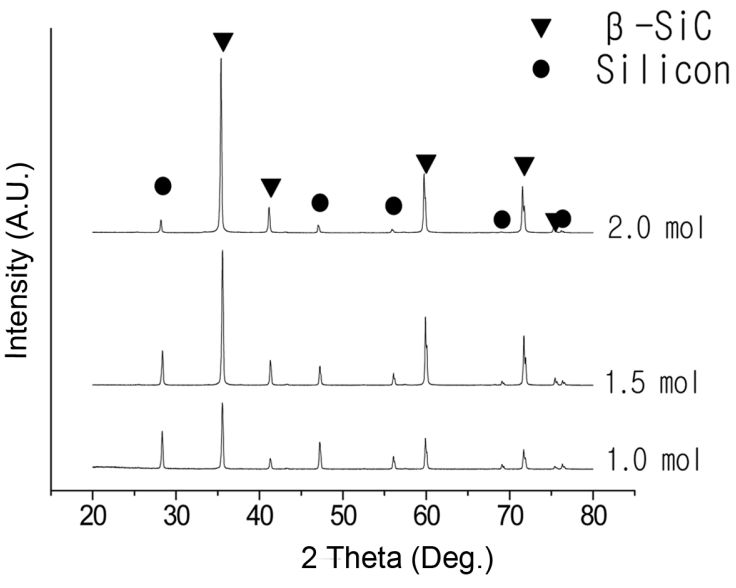

Fig. 4. $\mathrm{XRD}$ results with different $\mathrm{C} / \mathrm{Si}$ mole ratios $(1.0,1.5$, 2.0) after heat treatment at $1550^{\circ} \mathrm{C}$.

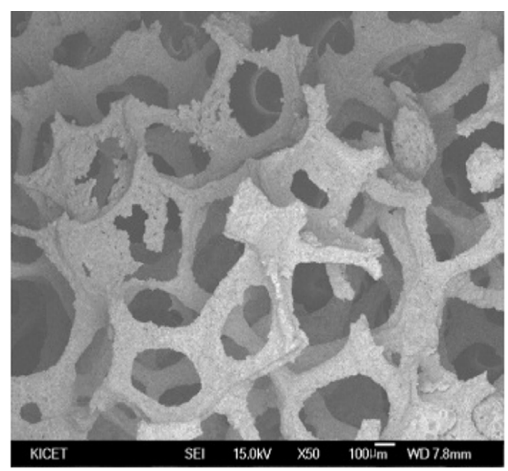

(c) $\mathrm{C} / \mathrm{Si}$ mole ratio : 2.0

Fig. 5. SEM image of porous silicon carbide with $\mathrm{C} / \mathrm{Si}$ mole ratio $1.0,1.5$, and 2.0 after heat treatment at $1550^{\circ} \mathrm{C}$.

소결체의 비표면적 및 기공특성에 영향을 미치는 것으로 판단된다.

폴리우레탄 함침 슬러리의 $\mathrm{C} / \mathrm{Si}$ 몰비 변화에 따른 광물 생성 변화를 파악하기 위하여 $\mathrm{Si}$ 함침 후 $1550^{\circ} \mathrm{C}$ 에서 열 처리한 시료의 $\mathrm{XRD}$ 를 측정하였으며 측정결과를 Fig. 4에 나타내었다. $\mathrm{XRD}$ 측정결과, $\mathrm{C} / \mathrm{Si}$ 몰비가 $1.0,1.5$ 및 2.0 으로 증가함에 따라서 $\mathrm{Si}$ 피크 크기가 점차 감소하는 것 을 알 수 있는데, 이것은 $\mathrm{C} / \mathrm{Si}$ 몰비가 증가할수록 $1420^{\circ} \mathrm{C}$ 열처리 과정에서 미반응 잔류카본 생성량이 증가하고 이 렇게 생성된 잔류카본이 추가로 함침된 실리콘과 $1550^{\circ} \mathrm{C}$ 에서 효율적으로 반응하면서 평균기공경과 기공부피 감 소에 영향을 주기 때문인 것으로 판단된다.

$\mathrm{C} / \mathrm{Si}$ 몰비를 $1.0,1.5$ 및 2.0으로 변화하여 열처리하였을 때 다공성 세라믹시료의 기공특성을 $\operatorname{SEM}($ 배율 50)을 이 용하여 측정하였으며 Fig. 5에 나타내었다. 또한 $1550^{\circ} \mathrm{C}$ 에서 2차 열처리한 폼 형태의 다공성 탄화규소의 미세구 조 특성을 살펴보기 위하여 $\mathrm{C} / \mathrm{Si}$ 몰비 1.0 과 2.0 조건에 서 열처리한 시편 표면의 $\mathrm{SEM}$ 이미지 및 $\mathrm{Si}$ 성분에 대 한 SEM mapping을 실시하였으며, 측정결과를 Fig. 6에

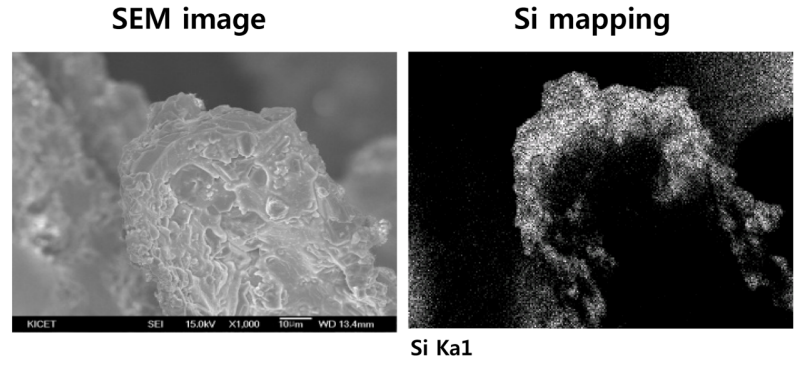

(a) $\mathrm{C} / \mathrm{Si}$ mole ratio: 1.0

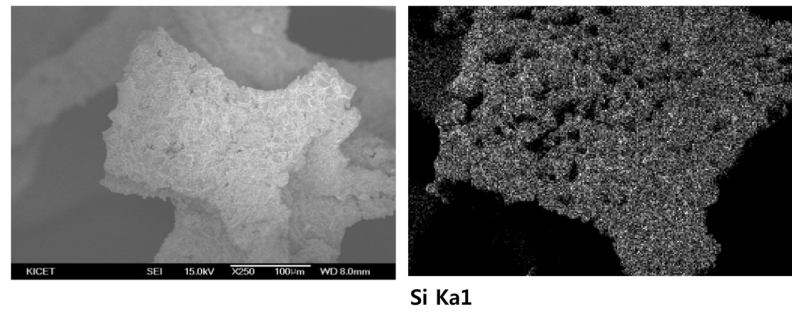

(b) $\mathrm{C} / \mathrm{Si}$ mole ratio: 2.0

Fig. 6. SEM image and Si mapping results of porous silicon carbide with $\mathrm{C} / \mathrm{Si}$ mole ratios 1.0 and 2.0 after heat treatment at $1550^{\circ} \mathrm{C}$. 
나타내었다. SEM 측정결과 미세한 결정립이 표면에 융 착되어 있으며 $\mathrm{C} / \mathrm{Si}$ 몰비 2.0 의 조건에서 미세한 균열이 존재함을 확인할 수 있었다. SEM mapping 측정결과, $\mathrm{C} /$ $\mathrm{Si}$ 몰비 1.0 의 조건에서 다공체 표면 위치별로 $\mathrm{C}$ 과 $\mathrm{Si}$ 성 분이 불균일하게 분포되어 있는 반면에 $\mathrm{C} / \mathrm{Si}$ 몰비 2.0 조 건에서는 다공체 표면 위치별로 $\mathrm{C}$ 과 $\mathrm{Si}$ 성분이 상대적으 로 균일하게 분포되어 있어 $1550^{\circ} \mathrm{C}$ 반응조건에서 $\mathrm{Si}$ 이 $\mathrm{C}$ 성분과 균일하고 효율적으로 반응한 것을 추정할 수 있다.

\section{4. 결 론}

폴리우레탄 폼을 템플릿으로 사용하는 고분자 복제 템 플릿 방법을 이용하여 폼 형태의 다공성 탄화규소를 제 조하였으며, 세라믹 함침 슬러리에서의 $\mathrm{C} / \mathrm{Si}$ 몰비 변화 및 열처리 조건변화에 따른 다공성 탄화규소의 기공특성과 미세구조 변화를 살펴보았다.

$1420^{\circ} \mathrm{C}$ 열처리 조건에서는 함침 슬러리 원료에서 $\mathrm{C} / \mathrm{Si}$ 몰비를 $1.0,1.5$ 및 2.0 으로 증가함에 따라서 열처리물의 비표면적이 $61.15 \mathrm{~m}^{2} / \mathrm{g}, 75.08 \mathrm{~m}^{2} / \mathrm{g}$ 및 $104.54 \mathrm{~m}^{2} / \mathrm{g}$ 으로 증 가하였다. 하지만 실리콘 함침 후 2 차 열처리 $\left(1550^{\circ} \mathrm{C}\right)$ 조 건에서는 비표면적이 $0.86 \sim 1.17 \mathrm{~m}^{2} / \mathrm{g}$ 으로 급격히 저하되 었으며, 특히 1 차 열처리과정에서 $\mathrm{C} / \mathrm{Si}$ 몰비가 증가하여 비표면적이 증가할 수록 $1550^{\circ} \mathrm{C}$ 에서 열처리한 시료의 비 표면적이 오히려 감소함을 확인할 수 있었다. 이러한 결 과는 실리콘과 카본과의 반응에 의한 탄화규소 광물 생 성과 밀접한 관련이 있으며, $1550^{\circ} \mathrm{C}$ 에서는 카본에 대한 실리콘의 접촉각이 작아지기 때문에, $\mathrm{C} / \mathrm{Si}$ 몰비가 증가하 여 잔류한 미 반응 카본성분이 실리콘과 용이하게 반응 하여 탄화규소를 생성하기 때문인 것으로 판단되었다. 다 공성 탄화규소의 부피밀도, XRD 및 $\mathrm{SEM}$ 분석결과로부 터 $\mathrm{C} / \mathrm{Si}$ 몰비 1.0 조건에서 보다는 카본함량이 많은 $\mathrm{C} / \mathrm{Si}$ 몰비 2.0 조건에서 실리콘과 카본이 균일하고 효율적으로 반응해서 다공성 탄화규소 생성에 효율적인 것을 확인할 수 있었다.

\section{Acknowledgment}

본 연구는 산업통상자원부 청정생산기반 전문기술개발사 업(No. 10038591)과 환경부환경기술개발사업(RE201403136) 의 연구비 지원을 통하여 수행되었으며, 이에 감사 드립니다.

\section{REFERENCES}

1. P. Pastila, V. Helanti, A. P. Nikkilä, and T. Mäntylä, "Environmental Effects on Micro Structure and Strength of SiC based Hot Gas Filters," J. Eur. Ceram. Soc., 21 [9] 1261-68 (2001).

2. J. Y. Won, S. R. Kim, Y. H. Kim, D. K. Shin, Y. J. Lee, and
W. T. Kwon, "Preparation of Porous Silicon Carbide Foam Using a Polymer Replica Method(in Korean)," J. Environ. Therm. Eng., 11 [1] 6-12 (2014).

3. Y. Jiao, C. Jiang, Z. Yang, J. Liu, and J. Zhang, "Synthesis of Highly Accessible ZSM-5 Coatings on SiC Foam Support," Microporous Mesoporous Mater., 181 201-07 (2013).

4. J. H. Eom, Y. W. Kim, and I. H. Song, "Effect of SiC Filler Content on Microstructure and Flexural Strength of Highly Porous SiC Ceramics Fabricated from Carbon-Filled Polysiloxane(in Korean)," J. Korean Ceram. Soc., 49 [6] 625-30 (2012).

5. S. R. Kim, W. T. Kwon, Y. H. Kim, J. I. Kim, Y. J. Lee, H. J. Lee, and S. C. Oh, "Additive Effects on Sintering of Si/ SiC Mixtures(in Korean)," Kor. J. Mater. Res., 22 [22] 70105 (2012).

6. A. R. Studart, U. T. Gonzenbach, E. Tervoort, and L. J. Gauckler, "Processing Routes to Macroporous Ceramics : A Review," J. Am. Ceram. Soc., 89 [6] 1771-89 (2006).

7. S. Ahmad, M. A. Latif, H. Taib, and A. F. Ismail, "Short Review : Ceramic Fabrication Techniques for Wastewater Treatment Application," Adv. Mat. Res., 795 5-8 (2013).

8. T. Ota, M. Takahashi, T. Hibi, M. Ozawa, S. Suzuki, Y. Hikichi, and H. Suzuki, "Biomimetic Process for Producing SiC "Wood"," J. Am. Ceram. Soc., 78 [12] 3409-11 (1995).

9. P. Sepulveda, "Gelcasting Foams for Porous Ceramics," Am. Ceram. Soc. Bull., 76 [10] 61-65 (1997).

10. I. Fukuura and T. Asano, "Fabrication and Properties of Some Oxide Ceramics: Alumina, Mullite and Zirconia," 165-74 in Fine Ceramics, Ed. by S. Saito. Elsevier, New York, 1985.

11. X. W. Zhu, D. L. Jiang, S. H. Tan, and Z. Zhang, "Improvement in the Strut Thickness of Reticulated Porous Ceramics," J. Am. Ceram. Soc., 84 [7] 1654-56 (2001).

12. M. R. Nangrejo and M. J. Edirisinghe, "Porosity and Strength of Silicon Carbide Foams Prepared Using Preceramic Polymer," J. Porous Mater., 9 [2] 131-40 (2002).

13. H. Wang, X. Li, J. Yu, and D. Kim, "Fabrication and Characterization of Ordered Macroporous PMS-derived SiC from a Sacrificial Template Method," J. Mater. Chem., 14 1383-86 (2004).

14. J. H. Eom, Y. W. Kim, and S. Raju, "Processing and Properties of Macroporous Silicon Carbide Ceramics : A review," J. Asian. Ceram. Soc., 1 220-42 (2013).

15. J. Won, Y. J. Lee, J. I. Kim, Y. Kim, S. R. Kim, H. J. Lee, T. K. Ko, M. Lee, and W. T. Kwon, "A Study on the Pore Structure Control with Heat Treatment Conditions of Waste Tire Carbon Residue," J. Kor. Inst. Res. Recycl., 22 [2] 1-7 (2013).

16. J. G. Li and H. Hausner, "Wetting and Adhesion in Liquid Silicon/Ceramic Systems," Mater. Lett., 14 329-32 (1992).

17. Z. Yuan, W. Huang, and K. Mukai "Wettability and Reactivity of Molten Silicon with Various Substrates," Appl. Phys. A, Mater., 78 [4] 617-22 (2004).

18. Z. Zhang, F. Wang, X. Yu, Y. Wang, and Y. Yan, "Porous Silicon Carbide Ceramics Produced by a Carbon Foam Derived from Mixtures of Mesophase Pitch and Si Particles," J. Am. Ceram. Soc., 92 [1] 260-63 (2009). 